\title{
SINGLE TESTICULAR METASTASIS MIMICKING PRIMARY TESTICULAR NEOPLASM: A RARE MANIFESTATION OF PROSTATE CANCER
}

\author{
CARLOS M. N. JESUS, JOSE GOLDBERG, JOAO L. V. CAMARGO \\ Departments of Urology and Pathology, Botucatu Medicine School, Paulista State University, UNESP, \\ Botucatu, Sao Paulo, Brazil
}

\begin{abstract}
The incidence of secondary testicular tumors ranges from 0.02 to $2.5 \%$ among autopsies in general. With the exception of leukemias and lymphomas, prostate cancer is the most common primary site. It is diagnosed in autopsies or incidentally, following therapeutic orchiectomies in more advanced stages of the disease.

In the present report, we show a case of testicular metastasis derived from prostate neoplasm whose clinical presentation as a single metastasis was similar to a primary testicular neoplasm. The diagnosis was evidenced after orchiectomy by histological examination and immunohistochemical tests.
\end{abstract}

Key words: testis; neoplasm metastasis; prostatic neoplasms

Int Braz J Urol. 2005; 31: 54-56

\section{INTRODUCTION}

Prostate adenocarcinoma is the most frequently diagnosed neoplasm in men and its natural history is largely known. The most common metastatic sites are iliac lymph nodes, bones and lungs, then followed more rarely by bladder, liver, adrenal and brain $(1,2)$. The testis is a rare site for prostate cancer metastases and is usually found in autopsies or incidentally after therapeutic orchiectomies for advanced disease. In this paper, we report one case of testicular metastasis from prostate cancer mimicking a primary testicular tumor in a young patient.

\section{CASE REPORT}

A 45-year old Caucasian patient presented increased volume and sensation of heaviness in his left testis for 2 months. Upon physical examination, he presented increased volume in the left testis with hardened consistency, smooth surface and absence of inflammatory signs. Two years earlier, the patient had undergone radical prostatectomy due to Gleason 9 prostate adenocarcinoma, and one year earlier he showed an increase in prostate specific antigen (PSA) levels, which was interpreted as a progression of disease, and hormone therapy with cyproterone acetate was used to control the disease. Bone scintigraphy and chest X-radiography were normal.

A scrotal ultrasound was performed, which showed an enlarged testis $(5 \times 3 \times 3 \mathrm{~cm})$ with heterogeneous parenchyma and multiple calcifications. The spermatic cord and epididymis had normal shape and outline.

Due to the main suspicion that this was a primary testicular tumor, orchiectomy was performed by inguinal access. Macroscopically, the testis showed irregular external shape, with whitish aspect, vague limits, and a peripheral mass dislodging the normal testicular parenchyma. The histological examination 
revealed a solid, non-differentiated tumor, which did not suggest a primary testicular tumor. There was tubular infiltration as well in the rete testes and epididymis (Figure-1). The immunohistochemical panel confirmed the prostate as a primary site due to the positivity of cytokeratins AE1/AE3 and PSA and the negativity of classical markers of germinative tumors such as the antigen CD30, human chorionic gonadotropin ( $\beta$-HCG), alpha-fetoprotein (AFP) and placental alkaline phosphatase (Figure-2).

Serum levels of $\beta$-HCG, AFP and lactic dehydrogenase were normal. The pre-operative PSA, which was $4.13 \mathrm{ng} / \mathrm{mL}$ decreased to $1.22 \mathrm{ng} / \mathrm{mL}$ within 2 months of the procedure. The patient has been followed with no progression of the disease found to the present moment.

\section{COMMENTS}

Testicular metastases are uncommon phenomena that are present in 0.02 to $2.5 \%$ of autopsies, with approximately 200 cases being reported in the literature (1). Tumors that most commonly send metastases to the testis are prostate, lung, melanoma and kidney. Testicular metastases are rarely derived from stomach, pancreas, bladder, rectum or penis (2).

This case shows a rare finding of testicular metastasis deriving from a prostate neoplasm, which was clinically observed through an increase in left scrotal volume associated with young age, a fact that is uncommon in this neoplasm. Most cases of metastases from prostate cancer are evidenced by autopsies or palliative bilateral orchiectomies aimed to control advanced disease in elderly patients. Additionally, the metastasis was single, with no metastases detected in other organs, stressing its rarity.

Microscopically, the neoplasm had a diffuse testicular involvement without preserving the seminiferous tubules (3). This feature, associated with the non-differentiated nature of the neoplasm as well as the clinical findings, established primary testicular neoplasm as the main differential diagnosis. The diagnosis of metastatic prostate cancer was confirmed only by immunohistochemical analysis.

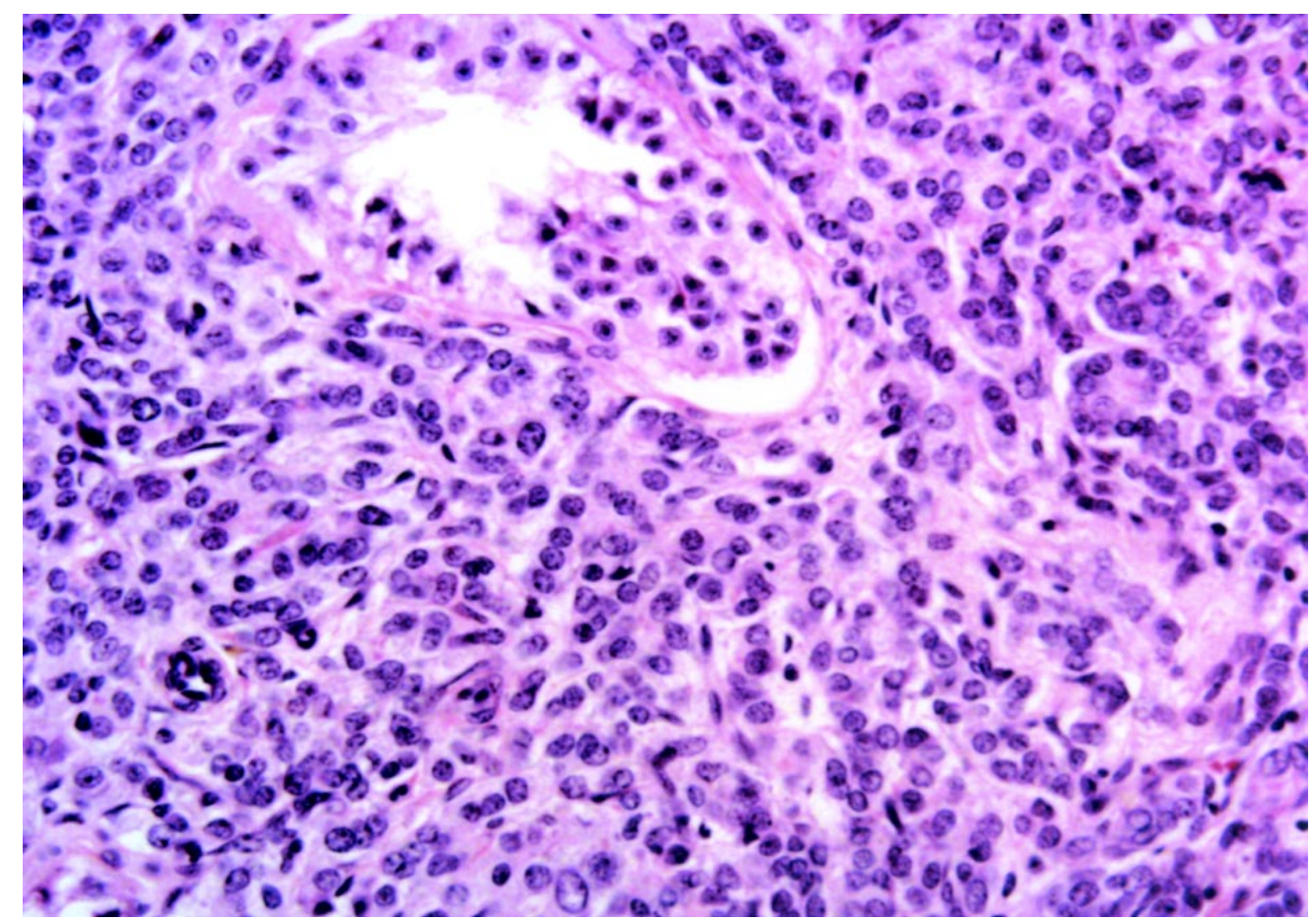

Figure 1 - Neoplasm infiltrating the testis. The seminiferous tubule is involved with non-differentiated neoplastic cells (HE, X250). 


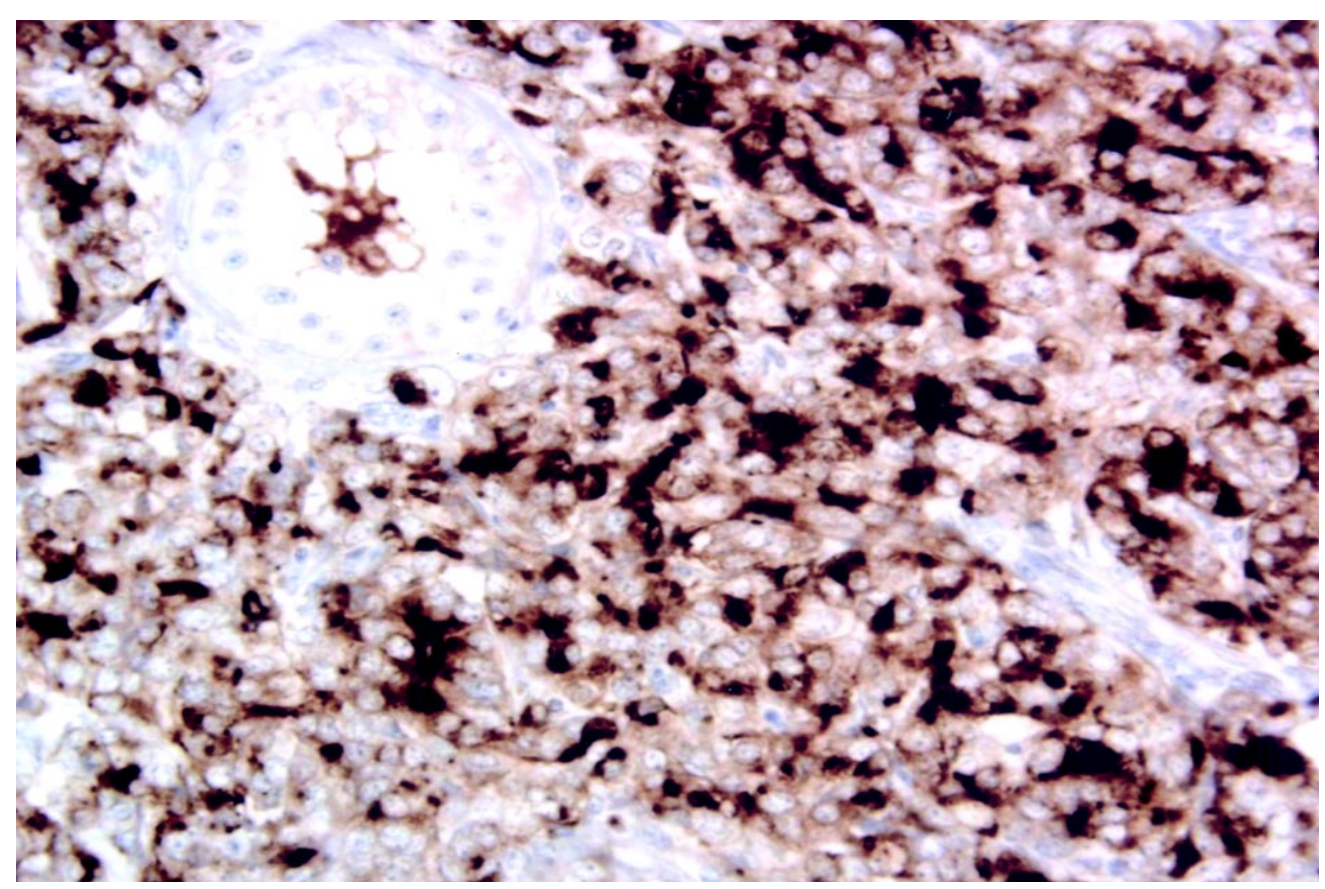

Figure 2 - Positive expression of prostate specific antigen (PSA) by metastatic cells involving a seminiferous tubule (Avidin-biotin peroxidase, anti-PSA antibody 1:20, X250).

\section{REFERENCES}

1. Dutt N, Bates AW, Baithun SI: Secondary neoplasms of the male genital tract with different patterns of involvement in adults and children. Histopathology. 2000; 37: 323-31.

2. Patel SR, Richardson RL, Kvols L: Metastatic cancer to the testes: a report of 20 cases and review of the literature. J Urol. 1989; 142: 1003-5.

3. Askari A, Faddoul A, Herrera H: Metastatic carcinoma to testicle. Urology. 1981; 17: 601-3.

Received: June 28, 2004 Accepted after revision: December 10, 2004

\section{Correspondence address:}

Dr. Carlos M. Nóbrega de Jesus

Dept. Urologia, Fac. de Medicina de Botucatu

Distrito de Rubião Júnior, S/N

Botucatu, SP, 18618-070, Brazil

Fax: + 5514 3811-6271

E-mail:marcio@fmb.unesp.br 